\title{
Thickness of the Buccal and Alveolar Bones Overlying Central Incisors: A Radiographic Iraqi Study
}

\author{
Nuhad A. Hassan ${ }^{1}{ }^{1}$ and Aseel S. Khazaal Al-Jaboori ${ }^{2}$ \\ ${ }^{1}$ Department of Oral Medicine, College of Dentistry, AL-Mustansiriyah University, Baghdad, Iraq \\ ${ }^{2}$ Department of Prosthetic Dentistry, College of Dentistry, AL-Mustansiriyah University, Baghdad, Iraq \\ Correspondence should be addressed to Nuhad A. Hassan; nuhad_alshammery@yahoo.com
}

Received 30 September 2021; Revised 22 January 2022; Accepted 26 January 2022; Published 9 February 2022

Academic Editor: Carlo Eduardo Medina-Solis

Copyright (c) 2022 Nuhad A. Hassan and Aseel S. Khazaal Al-Jaboori. This is an open access article distributed under the Creative Commons Attribution License, which permits unrestricted use, distribution, and reproduction in any medium, provided the original work is properly cited.

\begin{abstract}
Background. Initial bone thickness has a substantial impact on the success of dental implant treatments. The objective of the current study was to analyze the thickness of the buccal and alveolar bone at the central incisors using CBCT in relation to gender and side to determine the anatomical features and choose the best implant treatment option for minimizing the surgical complications. Methods. One hundred CBCT images were investigated (50 females and 50 males, aged 20 to 50 years old). The buccal bone thickness and alveolar bone thickness were evaluated for right and left sides of each subject at three sites; C: crest $(3 \mathrm{~mm})$; M: middle $(6 \mathrm{~mm}) ; \mathrm{A}$ : apical $(9 \mathrm{~mm})$ from the cementoenamel junction. Results. The mean thickness of buccal bone was less than $2 \mathrm{~mm}$ on the incisors according to side and gender. Buccal bone thickness revealed a statistically significant difference between right and left sides at the apical point in both females and males with $p$ values of $(p \leq 0.001)$ and $(0.001)$, respectively. The buccal bone thickness displayed statistically significant differences between genders at all sites. The alveolar thickness demonstrated similar significant differences between genders except for the crest site. Conclusions. Iraqi participants had about $1 \mathrm{~mm}$ buccal bone thickness at $3 \mathrm{~mm}$ apical from the CEJ in right and left central incisors with a progressive rise in bone thickness to be less than $2 \mathrm{~mm}$ at the apex. Alveolar bone also showed the same increase in bone thickness from crest to apex. Bone thickness was greater in males than females. The present study provided valuable CBCT data on bone thickness of the esthetic maxillary region as a preoperative analysis for establishing an immediate implant treatment plan with aesthetically pleasing long-term outcomes.
\end{abstract}

\section{Introduction}

Missing teeth are commonly treated with dental implants. The initial stability of dental implants and their survival rates are directly associated with patients' osseointegration ability [1]. The patients usually desire that their missing anterior teeth be replaced as soon as possible, so that they can resume their normal lives without the psychological problem of being edentulous and so that their appointments are reduced. Therefore, immediate implants placed between 0 and 7 days after tooth extraction came into existence to overcome this problem [2]. Devorah Schwartz-Arad concluded in their literature review article that immediate dental implants have a high survival rate when placed into fresh extraction sockets, and when inserted $3-5 \mathrm{~mm}$ beyond the apex and close to the crest of the alveolar bone [3]. The morphology, width, height, and density of the alveolar bone must be determined to choose the right size of the implant and the placement angle [4].

Bone thickness of the alveolar bone anteriorly is critical for dental implant therapy in terms of the esthetic outcomes. After tooth extraction, there will be a significant reduction in the buccolingual and apical-coronal extent of the alveolar region, which may affect the placement of implant-supported crown in the esthetic zone [5].

Moreover, sufficient buccal bone thickness in the anterior maxillary region is crucial for proper implant positioning. The thickness of the labial plate of the maxilla especially of the central incisors was reported to be very thin, necessitating extreme caution when inserting an implant 
$[6,7]$. Next to upper central tooth extraction and immediate implant placement, the facial bone that covers the roots of the tooth is prone to resorption more than the palatal plate, leading to the center of the ridge to move to the palatal direction [8]. The amount of resorption is really affected by the original bone thickness. The thinner bone will contribute to a greater bone loss, dehiscence, fenestration, and recession of the soft tissue, risking the aesthetics and success of the implant $[9,10]$.

As studies have shown variances in bone patterns in various people, it is extremely crucial to pick a site for the installation of dental implants before the treatment and to thoroughly evaluate the oral anatomy and the width of both the ridge and the alveolar crest [11].

Cone beam computed tomography (СBCT) is extremely important for evaluating the advantages of the bony components surrounding the teeth as compared to older techniques. This technology has the advantages of high resolution, being noninvasive, low radiation dosage, and being cost efficient [12]. CBCT images are the most used means of measuring buccal bone thickness (BBT) in comparison of gender, age, and tooth differences across different patients and among other factors [13, 14]. Vera et al. [15] stated that $\mathrm{CBCT}$ scans can identify the BBT and its condition in the concerned area as an indicator for prolonged success of the implant.

A number of researches have employed CT to investigate maxillary alveolar bone thickness in the skull, but it may be inefficient as only two-dimensional data are available [16]. Few investigations have been conducted on $\mathrm{CBCT}$, practically in the Iraqi population. Moreover, the anterior maxilla is esthetically sensitive for immediate dental implants position because of its particular anatomy. The objective of the current study was to analyze the thickness of the buccal and alveolar bone at the central incisors using $\mathrm{CBCT}$ in relation to gender and side of an Iraqi sample to determine the anatomical features and choose the best implant treatment option for minimizing the surgical complications.

\section{Materials and Methods}

One hundred СВСТ images were investigated (50 females and 50 males, aged 20 to 50 years old), who were referred from different departments needing CBCT for various dental treatments. For all research participants, the ethical principles established in the Helsinki Declaration of 1964 were implemented. The local ethical approval by the Scientific Committee of Oral Medicine Department was obtained (protocol 16; November 2020). Following their approval, all participants provided consent forms. The minimum sample size was estimated to be 45 patients in each group using $\mathrm{G} *$ Power 3.1.9.7 software and data generated through our pilot study.

The CBCT scanning was done by Myray, Italy, FOV $8 \times 8 \mathrm{~cm}$, voxel size $0.3 \mathrm{~mm}$, exposure time $9.34 \mathrm{~s}, \mathrm{kVp} 75$, $\mathrm{mA}$ 5. The CBCT scans clearly showed the front maxilla and central incisors. Teeth having a root canal, periapical lesion, periodontal disease, malformation, or treatment such as fillings, crowns, or bruising were eliminated from the research.

The evaluation of the central incisors was done by CBCT. The data was collected and repeated by the same radiologist after one week. The two readings were almost the same, though to assess the intraobserver reliability, a paired $t$-test was conducted for 10 random CBCT scans showing no significant difference. The mean of each 2 measurements was utilized in the statistics. The buccal bone thickness (BBT) and alveolar bone thickness (ABT) were evaluated at three sites, which are C: crest $(3 \mathrm{~mm}) ; \mathrm{M}$ : middle $(6 \mathrm{~mm}) ; \mathrm{A}$ : apical $(9 \mathrm{~mm})$ from the cementoenamel junction (CEJ), and vertical to the long axis of the tooth at each point. The right and left sides were evaluated for all subjects [17], Figure 1.

2.1. Statistical Analysis. Data analysis was conducted with SPSS software version 21. Shapiro-Wilk and Levene's tests were used to investigate the data's normality and homogeneity of variance respectively. The independent $t$-test was used to compare thickness data between genders. A $p$ value $\leq 0.05$ was considered statistically significant.

\section{Results}

The study involved 100 CBCT images (200 teeth), divided equally into male and female groups.

The means of buccal bone thickness (BBT) at the crest, middle, and apical sites of females on the left side were $(0.92 \pm 0.22),(1.17 \pm 0.16)$, and $(1.19 \pm 0.25)$, respectively. And they were $(0.90 \pm 0.25),(1.17 \pm 0.20)$, and $(1.47 \pm 0.32)$ for the right side, respectively. For males, the means of BBT at the three sites were $(1.00 \pm 0.09),(1.20 \pm 0.08)$, and $(1.35 \pm 0.21)$ for the left side, respectively. Likewise, they were (1.02 \pm 0.08$),(1.21 \pm 0.06)$, and $(1.48 \pm 0.27)$ for the right side, respectively. Regarding the sides, the left $\mathrm{BBT}$ showed statistically significant difference across genders on two points (C and A), in spite of the right side showing statistically significant difference at one point only $(\mathrm{C})$. The male groups had higher bone thickness than female groups at these points (Table 1).

In females, the mean thicknesses of the alveolar ridge (ABT) at the three sites (crest, middle, and apical) were (7.22 \pm 0.44$),(7.73 \pm 0.30)$, and $(8.44 \pm 0.40)$ for the left side, respectively. Besides, they were $(7.26 \pm 0.43),(7.79 \pm 0.42)$, and $(8.50 \pm 0.32)$ for the right side, respectively. Additionally, for males, the means were $(7.24 \pm 0.43),(8.24 \pm 0.34)$, and $(9.03 \pm 0.47)$ for the left side, respectively, while they were $(7.32 \pm 0.40),(8.21 \pm 0.36)$, and $(9.10 \pm 0.41)$ for the right side, respectively. The ABT on both sides was significantly different across gender (males showed higher bone thickness than females), except for the crest points (Table 2).

The $t$-test performed for comparison of the left and right sides of BBT by gender revealed statistically significant difference at only the apical points in both females (left side: $1.19 \pm 0.25$, right side: $1.47 \pm 0.32, p \leq 0.001$ ) and males (left side: $1.35 \pm 0.21$, right side: $1.48 \pm 0.27, p=0.001$ ). The comparison between the left and right sides of $\mathrm{ABT}$ expressed significant differences at crest and apical sites only 


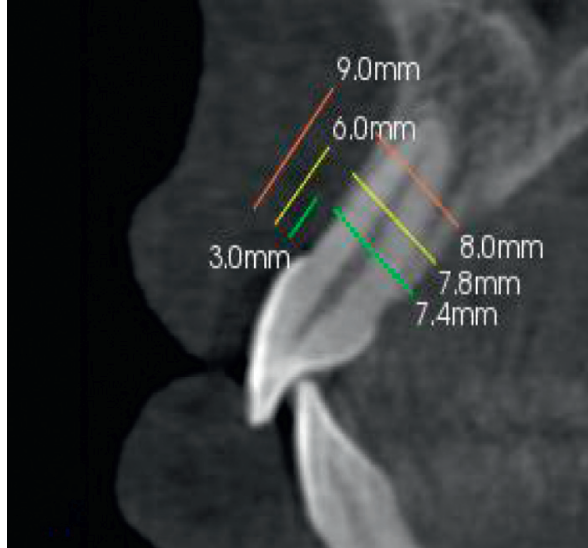

(a)

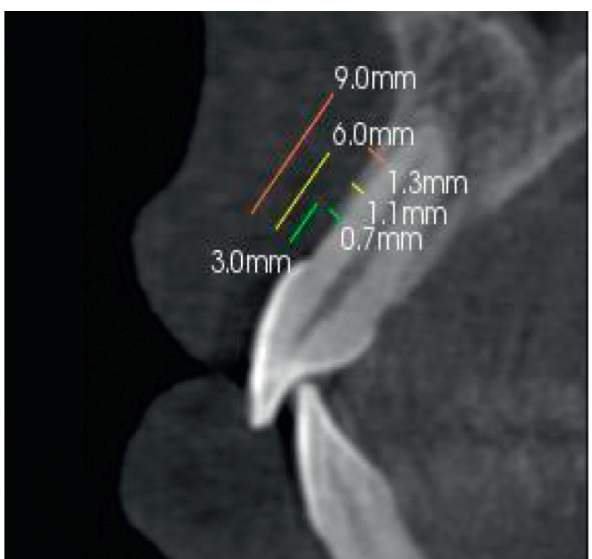

(b)

Figure 1: (a) Three locations for measuring alveolar bone thickness; (b) three sites for measuring buccal bone thickness.

TABle 1: Descriptive statistics of left and right buccal bone thickness $(\mathrm{mm})$ by gender with comparison of thickness between males and females according to side using $t$-test.

\begin{tabular}{lcccccc}
\hline & \multirow{4}{*}{$N$} & \multicolumn{2}{c}{ Mean } & \multicolumn{2}{c}{ Std deviation } & \multirow{2}{*}{ value } \\
& & Female & Male & Female & Male & \\
\hline Left crest & 50 & 0.92 & 1.00 & 0.22 & 0.090 & $0.013^{*}$ \\
Left middle & 50 & 1.17 & 1.20 & 0.160 & 0.080 & 0.252 \\
Left apical & 50 & 1.19 & 1.35 & 0.250 & 0.210 & $0.001^{*}$ \\
Right crest & 50 & 0.90 & 1.02 & 0.25 & 0.080 & $0.003^{*}$ \\
Right middle & 50 & 1.17 & 1.21 & 0.200 & 0.060 & 0.145 \\
Right apical & 50 & 1.47 & 1.48 & 0.320 & 0.270 & 0.986 \\
\hline
\end{tabular}

$N=$ number of sample, Std deviation: standard deviation, $p=$ probability value, ${ }^{*}$ Statistically significant $(p<0.05)$

Table 2: Descriptive statistics of left and right alveolar bone thickness $(\mathrm{mm})$ by gender with comparison of thickness between males and females according to side using $t$-test.

\begin{tabular}{lcccccc}
\hline & \multirow{2}{*}{$N$} & \multicolumn{2}{c}{ Mean } & \multicolumn{2}{c}{ Std deviation } & \multirow{2}{*}{ value } \\
& & Female & Male & Female & Male & \\
\hline Left crest & 50 & 7.22 & 7.24 & 0.440 & 0.430 & 0.827 \\
Right crest & 50 & 7.26 & 7.32 & 0.430 & 0.40 & 0.505 \\
Left middle & 50 & 7.73 & 8.24 & 0.300 & 0.340 & $\leq 0.001^{*}$ \\
Right middle & 50 & 7.79 & 8.21 & 0.42 & 0.360 & $\leq 0.001^{*}$ \\
Left apical & 50 & 8.44 & 9.03 & 0.400 & 0.470 & $\leq 0.001^{*}$ \\
Right apical & 50 & 8.50 & 9.10 & 0.320 & 0.410 & $\leq 0.001^{*}$ \\
\hline
\end{tabular}

$N=$ number of sample, Std deviation $=$ standard deviation, $p=$ probability value, ${ }^{*}$ High statistically significant $p \leq 0.001$.

in males where the right sides showed a higher mean values with $(p=0.032)$ and $(p=0.019)$, respectively, Table 3.

In Table 4 , the BBT displays statistically significant differences between genders at all sites. Bone thickness was greater in the males (crest: 1.01, middle: 1.205, apex: 1.415) than females (crest: 0.91, middle: 1.17, apex: 1.33). ABT demonstrated similar significant differences between genders except for the crest site.

Table 5 presents a statistically significant difference at the apical point for BBT concerning side, as bone thickness was increased at the right side $(1.54 \pm 0.34)$ compared to the left
TABLe 3: T-test between left and right bone thickness $(\mathrm{mm})$ for both males and females by sites.

\begin{tabular}{lccc}
\hline & $N$ & \multicolumn{2}{c}{$p$ value } \\
& & Female & Male \\
\hline Crest buccal bone thickness & 50 & 0.3770 & 0.3760 \\
Middle buccal bone thickness & 50 & 0.9920 & 0.3200 \\
Apical buccal bone thickness & 50 & $\leq 0.001^{* *}$ & $0.001^{* *}$ \\
Crest alveolar bone thickness & 50 & 0.2440 & $0.032^{*}$ \\
Middle alveolar bone thickness & 50 & 0.2910 & 0.4030 \\
Apical alveolar bone thickness & 50 & 0.3290 & $0.019^{*}$ \\
\hline
\end{tabular}

$p=$ probability value, ${ }^{*}$ Statistically significant $(p<0.05),{ }^{* *}$ High statistically significant.

TABLe 4: $T$-test of bone thickness $(\mathrm{mm})$ between males and females according to site.

\begin{tabular}{lcccc}
\hline & \multicolumn{4}{c}{ Mean } \\
& $N$ & Male & Female & $p$ value \\
\hline Crest buccal bone thickness & 100 & 1.01 & 0.91 & $0.015^{*}$ \\
Middle buccal bone thickness & 100 & 1.205 & 1.17 & $0.013^{*}$ \\
Apical buccal bone thickness & 100 & 1.415 & 1.33 & $0.003^{*}$ \\
Crest alveolar bone thickness & 100 & 7.28 & 7.24 & 0.505 \\
Middle alveolar bone thickness & 100 & 8.22 & 7.76 & $0.003^{*}$ \\
Apical alveolar bone thickness & 100 & 9.06 & 8.47 & $0.004^{*}$ \\
\hline$p=$ probability value, * Statistically significant $(p<0.05)$.
\end{tabular}

side (1.42 \pm 0.34$)$. Similar significant results were observed at the crest (right side: $6.11 \pm 1.29$, left side: $6.05 \pm 1.29$ ) and apical points (right side: $8.29 \pm 1.15$, left side; $8.21 \pm 1.12$ ) of ABT $(p<0.05)$.

The relationship between left and right BBT was highly statistically significant for the three sites $(r=0.52, r=0.51$ and $r=0.68)$, respectively $(p \leq 0.001)$. For ABT, the same statistically significant values were recorded $(r=0.98$, $r=0.89$, and $r=0.84$ ), respectively.

\section{Discussion}

In dentistry, implant surgery is now the most prevalent therapy for lost teeth. Related research has shown that a 
TABle 5: Descriptive statistics of bone thickness $(\mathrm{mm})$ by side and comparison of left and right thickness according to site.

\begin{tabular}{|c|c|c|c|c|c|c|}
\hline & \multirow{2}{*}{$N$} & \multicolumn{2}{|c|}{ Mean } & \multicolumn{2}{|c|}{ Std deviation } & \multirow{2}{*}{$p$ value } \\
\hline & & Left & Right & Left & Right & \\
\hline Crest buccal bone thickness & 100 & 0.990 & 1.00 & 0.1970 & 0.2480 & 0.630 \\
\hline Middle buccal bone thickness & 100 & 1.24 & 1.26 & 0.195 & 0.248 & 0.300 \\
\hline Apical buccal bone thickness & 100 & 1.42 & 1.54 & 0.3420 & 0.3430 & $\leq 0.001^{* *}$ \\
\hline Crest alveolar bone thickness & 100 & 6.05 & 6.11 & 1.297 & 1.291 & $\leq 0.001^{* *}$ \\
\hline Middle alveolar bone thickness & 100 & 7.17 & 7.19 & 1.047 & 1.046 & 0.505 \\
\hline Apical alveolar bone thickness & 100 & 8.21 & 8.29 & 1.127 & 1.157 & $0.047^{*}$ \\
\hline
\end{tabular}

$N=$ number of samples, Std deviation $=$ standard deviation, $p=$ probability value, ${ }^{*}$ Statistically significant $(p<0.05),{ }^{* *}$ High statistically significant $p \leq 0.001$.

positive bone state leads to greater osseointegration and an increased lifespan of dental implants; hence, a preoperative examination of the jawbone health is required $[18,19]$.

The current work applied CBCT to investigate bone thickness in the implantation sites as a presurgical assessment for the outer boney layer and the alveolar bone, which has proved to be useful for the patients in relevant studies using the same technology $[20,21]$. CBCT has become the standard option for implant position planning, especially in esthetic zone. For example, augmentation surgical procedure may be required to enhance the bone around the dental implant if alveolar bone atrophy determined by CBCT was severe [9]. Compared to the palatal bone, the labial cortical plate at the anterior maxillary region is thinner, and resorption occurs more easily after teeth extraction [8]. The mid-buccal bone recession was about $0.5 \mathrm{~mm}$ after the first year of dental implantation according to a prospective study of single immediate implant placement at the maxillary anterior region [22]. In addition to that, excessive force applied to a thin buccal plate by implant insertion might cause microfractures and crestal bone loss. Therefore, it is critical to guarantee the existence of hard tissues to perform the implantation process without serious complications by using the right implant site and angling in the alveolar bone.

Moreover, the prevalence and rate of peri-implant soft tissue marginal recession that happens in the labial and interproximal sites after implant placement should be a major concern for clinicians from the dental implant aesthetics perspective. The mean free gingival recession around a single-tooth implant was found to be $0.5-1 \mathrm{~mm}$ [23]. Patients with thin scalloped gingiva were shown to be more prone to recession, whereas the thick-flat biotype was found to be a significant determining factor in achieving a satisfying esthetic outcome in implant restorations [24]. Further, certain periodontists have observed that thin alveolar contours are covered by thin gingival forms, suggesting that gingival contours are associated with underlying bone anatomy. As a result, soft tissue aesthetics surrounding implants are primarily influenced by bone anatomy [25].

With a number of modern studies [26, 27], the current work conducted on data to evaluate the thickness surrounding natural dentition. The soundness of determining BBT over natural teeth by CBCT has been approved and applied by many studies to find the length between CEJ and crest of the bone plus BBT of anterior teeth [28]. When assessing the thickness of the labial walls, choosing a reference point appears to be crucial. In the present study, CEJ was used as a reference point in accordance with previous studies using $3 \mathrm{~mm}$ distance $[17,29]$. Measurements of bone thickness were also performed at 1 to $5 \mathrm{~mm}$ apical to the labial bone crest [13].

Clinicians have a public opinion that $2 \mathrm{~mm}$ is the smallest required thickness of the buccal wall to preserve the length of the alveolar crest and to calculate the quantity of crest resorption vertically after extraction [30]. Thus, due to the esthetic effect and long-term repercussions, the BBT must be carefully considered prior to tooth extraction and implant insertion. According to a one-year follow-up study, labial plate of 1-2 mm was suggested for better esthetic outcomes in immediate implant treatment, because enormous gingival recession and bone resorption were found in patients with a thickness of less than $0.5 \mathrm{~mm}$ [31]. Thus, in cases with thin buccal bone walls, dentists must consider the use of bone augmentation or graft material in immediate implant treatment plan [32]. In the current work, the mean of BBT on the left side was increased from $0.92 \mathrm{~mm}$ at the crest to $1.19 \mathrm{~mm}$ at the apex in females, while it was $0.90 \mathrm{~mm}$ coronally and $1.47 \mathrm{~mm}$ apically on the right side. According to males, it was $1.00 \mathrm{~mm}$ at the crest and increased to $1.35 \mathrm{~mm}$ at the apex of the left side. As for the right side, it was $1.02 \mathrm{~mm}$ coronally and $1.48 \mathrm{~mm}$ apically.

Januário et al. and other authors $[13,33]$ observed that BBT was slim and rarely $>2 \mathrm{~mm}$ at different distances from CEJ during their studies by $\mathrm{CBCT}$, which was compatible with the current outcome. Another study looked at BBT for 73 individuals without recording results exceeding $2 \mathrm{~mm}$ in bone thickness [30]. However, the finding was in disagreement with dos Santos et al. [34] who noticed that BBT was $<1 \mathrm{~mm}$ in the majority of patients through examination of 202 CBCT (1463 teeth), while, in another prior study using 50 CBCT scan of maxilla, less than $10 \%$ of buccal bone sites had more than $2 \mathrm{~mm}$ thickness and in $14.4 \%$ of the central incisor buccal bone sites were $\geq 2 \mathrm{~mm}$ [35]. This variation in BBT results may be related to the difference in sample sizes, age, and gender.

The present work revealed a progressive rise in the thickness of the buccal and alveolar bone from the crest towards the apex. Koç et al. [36] and authors of other studies $[37,38]$ concluded a coinciding view with the present finding, indicating a steady increase in thickness in an apical direction. The finding was also consistent with that of Deguchi et al. [39], who discovered that the thickness of cortical bone increases with height and decreases with depth. For central incisors, the BBT was thicker at the apex and 
thinner at the crest. This provides insight into the thickness, reducing the risk of implant complications, as stated by Prakash et al. [40]. Another publication mentioned that the alveolar width of the central incisor diminished from the apical to crest direction [29], which is in line with the current work. In contrast, AlTarawneh et al. [41] reported that the mean measure of labial plates decreased towards the apical portion. This discrepancy might be attributed to the characteristics of the included cases as well as the different measuring depth used.

The absence of significance in the current study among $\mathrm{BBT}$ on the left and right sides was observed for the first two points (Table 3) since only the apical point was significant. Lee et al. [29] found no significant difference between the left and right BBT through a study of twenty participants.

The present study described the statistically significant difference of the left BBT between genders on two points (C and $A$ ), in spite of the right BBT being statistically significant at one point only (C). Fuentes et al. [35] noted that the BBT of the right central did not vary by gender, in contrast to the left central that showed a significant difference by this factor, and proposed that gender is not an indicator for thickness since this exhibited a different impact by gender.

The current finding indicated that males possess larger BBT than females at various root levels regardless of sides. The result is supported by specific past study groups $[26,29,42]$. Additionally, Adiguzel et al. [43] concluded that gender was significantly related to the BBT in the maxilla. According to the Cassetta et al. [44] study on 48 computed tomography scans, men had thicker alveolar cortical bone than women, and the alveolar crest thickens as it approaches the apex. Age could also be a deciding factor according to the literature. It has been noted that the thickness of the labial bone at the cervical part decreases with age [45], and that postmenopausal women have much thinner labial bone [37].

This study concluded gender differences in thickness of the alveolar ridge that women had smaller thickness than men except for the crest site. Men had stronger muscles for mastication than women to apply higher biting force [46]. Uner et al. [17] conducted a study on 160 CBCT (320 teeth) at 3,6 , and $9 \mathrm{~mm}$ depths below the crest with ages ranging from 21 to 53 and suggested a gender difference. Males had wider alveolar ridges than females in every location studied, which approximated current work except for the crest, which was statistically nonsignificant. Likewise, Lim et al. [47] asserted that women had a smaller ridge width than men during CBCT study of 32 subjects (13 men; 19 women).

Resorption of the buccal plate is more likely to impact the anterior regions than the posterior ones because the resorption is extra serious when the walls are first thinner. CBCT is the optimal method for preventing compromises in esthetic reconstruction [48]. It enables multiple measures at several sites and the existent bone property [49]. The research had certain limitations, which included the age impact. Second, the study only covered Iraqi patients. Several outcomes may not apply to other ethnicities. Finally, when the bone plate is exceedingly thin, $\mathrm{CBCT}$ readings may produce substantial inaccuracies and overestimations.

\section{Conclusions}

The present study presents valuable information regarding the thickness of buccal walls in the esthetic maxillary central incisor region in an Iraqi population as a preoperative analysis for establishing immediate implant treatment plan for aesthetically pleasing long-term outcomes.

Iraqi participants had about $1 \mathrm{~mm}$ buccal bone thickness at $3 \mathrm{~mm}$ apical from the CEJ in right and left central incisors sites with a progressive rise in the thickness to be less than $2 \mathrm{~mm}$ at the apex. In the esthetic maxillary region, there is a significant preponderance of thin $\mathrm{BBT}$, which should be considered when performing dental procedures, such as tooth extractions or immediate implants. Alveolar bone also showed the same increase in bone thickness from crest to apex. Bone thickness was greater in males than females.

\section{Data Availability}

The data used to support the findings of this study are available from the corresponding author upon request.

\section{Conflicts of Interest}

The authors declared that there were no conflicts of interest.

\section{Authors' Contributions}

Nuhad A. Hassan conceptualized the study, conducted investigation, wrote the original draft of the manuscript, critically reviewed intellectual contents, and approved the final version to be published. Aseel S. Khazaal Al-Jaboori formulated the methodology, reviewed and edited the manuscript, visualization, and supervision, critically reviewed intellectual contents, and approved the final version to be published.

\section{References}

[1] D. G. K. Hong and J.-h. Oh, "Recent advances in dental implants," Maxillofacial Plastic and Reconstructive Surgery, vol. 39, no. 1, p. 33, 2017.

[2] G. Gomez-Roman, W. Schulte, B. d'Hoedt, and D. AxmanKrcmar, "The Frialit-2 implant system: five-year clinical experience in single-tooth and immediately post extraction applications," The International Journal of Oral \& Maxillofacial Implants, vol. 12, no. 3, pp. 299-309, 1997.

[3] D. Schwartz-Arad and G. Chaushu, "The ways and wherefores of immediate placement of implants into fresh extraction sites: a literature review," Journal of Periodontology, vol. 68, no. 10, pp. 915-923, 1997.

[4] H. Eufinger, S. Konig, A. Eufinger, and E. Machtens, "Significance of the height and width of the alveolar ridge in implantology in the edentulous maxilla. Analysis of $95 \mathrm{ca}-$ daver jaws and 24 consecutive patients," Mund-, Kiefer- und Gesichtschirurgie, vol. 3, no. Suppl 1, pp. S14-S18, 1999.

[5] L. Schropp, A. Wenzel, L. Kostopoulos, and T. Karring, "Bone healing and soft tissue contour changes following single-tooth extraction: a clinical and radiographic 12-month prospective study," The International Journal of Periodontics \& Restorative Dentistry, vol. 23, no. 4, pp. 313-323, 2003. 
[6] J. Y. Han and G. U. Jung, "Labial and lingual/palatal bone thickness of maxillary and mandibular anteriors in human cadavers in Koreans," Journal of Periodontal \& Implant Science, vol. 41, no. 2, pp. 60-66, 2011.

[7] M. G. Araújo, J. C. C. da Silva, A. F. de Mendonça, and J. Lindhe, "Ridge alterations following grafting of fresh extraction sockets in man. A randomized clinical trial," Clinical Oral Implants Research, vol. 26, no. 4, pp. 407-412, 2015.

[8] U. Pal, G. Singh, S. Mohammad, N. Dhiman, R. Singh, and L. Malkunje, "Evaluation of implants placed immediately or delayed into extraction sites," National Journal of Maxillofacial Surgery, vol. 2, no. 1, pp. 54-62, 2011.

[9] A. Peterson, M. Wang, S. Gonzalez, D. Covell, J. Katancik, and H. Sehgal, "An in vivo and cone beam computed tomography investigation of the accuracy in measuring alveolar bone height and detecting dehiscence and fenestration defects," The International Journal of Oral \& Maxillofacial Implants, vol. 33, no. 6, pp. 1296-1304, 2018.

[10] C. Tomasi, M. Sanz, D. Cecchinato et al., "Bone dimensional variations at implants placed in fresh extraction sockets: a multilevel multivariate analysis," Clinical Oral Implants Research, vol. 21, no. 1, pp. 30-36, 2010.

[11] S. Baumgaertel and M. G. Hans, "Buccal cortical bone thickness for mini-implant placement," American Journal of Orthodontics and Dentofacial Orthopedics, vol. 136, no. 2, pp. 230-235, 2009.

[12] R. Kanomi, "Mini-implant for orthodontic anchorage," Journal of Clinical Orthodontics, vol. 31, no. 11, pp. 763-767, 1997.

[13] A. L. Januário, W. R. Duarte, M. Barriviera, J. C Mesti, M. G Araújo, and J Lindhe, "Dimension of the facial bone wall in the anterior maxilla: a cone-beam computed tomography study," Clinical Oral Implants Research, vol. 22, no. 10, pp. 1168-1171, 2011.

[14] H. Nowzari, S. Molayem, C. H. K. Chiu, and S. K. Rich, "Cone beam computed tomographic measurement of maxillary central incisors to determine prevalence of facial alveolar bone width $\geq 2 \mathrm{~mm}$," Clinical Implant Dentistry and Related Research, vol. 14, no. 4, pp. 595-602, 2012.

[15] C. Vera, I. J. De Kok, D. Reinhold et al., "Evaluation of buccal alveolar bone dimension of maxillary anterior and premolar teeth: a cone beam computed tomography investigation," The International Journal of Oral \& Maxillofacial Implants, vol. 27, no. 6, pp. 1514-1519, 2012.

[16] S. L. Lee, H. J. Kim, M. K. Son, and C. H. Chung, "Anthropometric analysis of maxillaryanterior buccal bone of Korean adults using cone-beam CT," The Journal of Advanced Prosthodontics, vol. 2, no. 3, pp. 92-96, 2010.

[17] D. D. Uner, B. S. Izol, and Z. Gorus, "Correlation between buccal and alveolar bone widths at the central incisors according to cone-beam-computed tomography," Nigerian Journal of Clinical Practice, vol. 22, no. 1, pp. 79-84, 2019.

[18] P. I. Brånemark, U. Breine, and R. Adell, "Intra-osseous anchorage of dental prostheses: I. Experimental studies," Scandinavian Journal of Plastic and Reconstructive Surgery, vol. 3, no. 2, pp. 81-100, 1969.

[19] P. I. Brånemark, B. O. Hansson, R. Adell et al., "Osseointegrated implants in the treatment of the edentulous jaw. Experience from a 10-year period," Scandinavian Journal of Plastic and Reconstructive Surgery. Supplementum, vol. 16, pp. 1-132, 1977.

[20] Y.-C. Ko, H.-L. Huang, Y.-W. Shen, J.-Y. Cai, L.-J. Fuh, and J.-T. Hsu, "Variations in crestal cortical bone thickness at dental implant sites in different regions of the jawbone,"
Clinical Implant Dentistry and Related Research, vol. 19, no. 3, pp. 440-446, 2017.

[21] A. Gupta, S. Rathee, J. Agarwal, and R. B. Pachar, "Measurement of crestal cortical bone thickness at implant site: a cone beam computed tomography study," The Journal of Contemporary Dental Practice, vol. 18, no. 9, pp. 785-789, 2017.

[22] R. Cornelini, F. Cangini, U. Covani, and T. G. Wilson Jr., "Immediate restoration of implants placed into fresh extraction sockets for single-tooth replacement: a prospective clinical study," The International Journal of Periodontics \& Restorative Dentistry, vol. 25, no. 5, pp. 439-447, 2005.

[23] C. D. Evans and S. T. Chen, "Esthetic outcomes of immediate implant placements," Clinical Oral Implants Research, vol. 19, no. 1, pp. 73-80, 2008.

[24] J. Y. K. Kan, K. Rungcharassaeng, K. Umezu, and J. C. Kois, "Dimensions of peri-implant mucosa: an evaluation of maxillary anterior single implants in humans," Journal of Periodontology, vol. 74, no. 4, pp. 557-562, 2003.

[25] C. Ochsenbein and S. Ross, "A reevaluation of osseous surgery," Dental Clinics of North America, vol. 13, no. 1, pp. 87-102, 1969.

[26] H. El Nahass and S. N. Naiem, "Analysis of the dimensions of the labial bone wall in the anterior maxilla: a cone-beam computed tomography study," Clinical Oral Implants Research, vol. 26, no. 4, pp. 57-61, 2015.

[27] V. C. Cook, A. M. Timock, J. J. Crowe, M. Wang, and D. A. Covell, "Accuracy of alveolar bone measurements from cone beam computed tomography acquired using varying settings," Orthodontics and Craniofacial Research, vol. 18, no. Suppl 1, pp. 127-136, 2015.

[28] Z. Zhou, W. Chen, M. Shen, C. Sun, J. Li, and N. Chen, "Cone beam computed tomographic analyses of alveolar bone anatomy at the maxillary anterior region in Chinese adults," Journal of biomedical research, vol. 28, no. 6, pp. 498-505, 2014.

[29] J.-E. Lee, C. Y. Jung, Y. Kim, Y.-A. Kook, Y. Ko, and J.-B. Park, "Analysis of alveolar bone morphology of the maxillary central and lateral incisors with normal occlusion," Medicina, vol. 55, no. 9, p. 565, 2019.

[30] F. Younes, A. Eghbali, M. Raes, T. De Bruyckere, J. Cosyn, and H. De Bruyn, "Relationship between buccal bone and gingival thickness revisited using non-invasive registration methods," Clinical Oral Implants Research, vol. 27, no. 5, pp. 523-528, 2016.

[31] X. Yang, T. Zhou, N. Zhou, and Y. Man, "The thickness of labial bone affects the esthetics of immediate implant placement and provisionalization in the esthetic zone: a prospective cohort study," Clinical Implant Dentistry and Related Research, vol. 21, no. 3, pp. 482-491, 2019.

[32] A. Barroso-Panella, J. Gargallo-Albiol, and F. HérnandezAlfaro, "Evaluation of bone stability and esthetic results after immediate implant placement using a novel synthetic bone substitute in the anterior zone: results after 12 months," The International Journal of Periodontics and Restorative Dentistry, vol. 38, no. 2, pp. 235-243, 2018.

[33] M. Nevins, M. Camelo, and S. De Paoli, "A study of the fate of the buccal wall of extraction sockets of teeth with prominent roots," The International Journal of Periodontics and Restorative Dentistry, vol. 26, no. 1, pp. 19-29, 2006.

[34] J. G. dos Santos, A. P. Oliveira Reis Durão, A. C. de Campos Felino, and R. M. Casaleiro Lobo de Faria de Almeida, "Analysis of the buccalbone plate, root inclination and alveolar bone dimensions in the jawbone. A descriptive 
study using cone-beam computed tomography," Journal of Oral \& Maxillofacial Research, vol. 10, no. 2, p. e4, 2019.

[35] R. Fuentes, T. Flores, P. Navarro, C. Salamanca, V. Beltrán, and E. Borie, "Assessment of buccal bone thickness of aesthetic maxillary region: a cone-beam computed tomography study," Journal of Periodontal \& Implant Science, vol. 45, no. 5, pp. 162-168, 2015.

[36] A. Koç, İ Kavut, and M. Uğur, "Assessment of buccal bone thickness in the anterior maxilla: a cone beam computed tomography study," Cumhuriyet Dental Journal, vol. 22, no. 1, pp. 102-107, 2019.

[37] C. Y. Zhang, C. DeBaz, G. Bhandal et al., "Buccalbone thickness in the esthetic zone of postmenopausal women: a CBCT analysis," Implant Dentistry, vol. 25, no. 4, pp. 478-484, 2016.

[38] A. Ono, M. Motoyoshi, and N. Shimizu, "Cortical bone thickness in the buccal posterior region for orthodontic miniimplants," International Journal of Oral and Maxillofacial Surgery, vol. 37, no. 4, pp. 334-340, 2008.

[39] T. Deguchi, M. Nasu, K. Murakami, T. Yabuuchi, H. Kamioka, and T. Takano-Yamamoto, "Quantitative evaluation of cortical bone thickness with computed tomographic scanning for orthodontic implants," American Journal of Orthodontics and Dentofacial Orthopedics: Official Publication of the American Association of Orthodontists, Its Constituent Societies, and the American Board of Orthodontics, vol. 129, no. 6, p. 721.e7, 2006.

[40] M. S. Prakash, D. M. Ganapathy, and T. Nesappan, "Assessment of labial alveolar bone thickness in maxillary central incisor and canine in Indian population using cone-beam computed tomography," Drug Invention Today, vol. 11, no. 3, pp. 712-714, 2019.

[41] S. AlTarawneh, A. AlHadidi, A. A. Hamdan, M. Shaqman, and E. Habib, "Assessment of bone dimensions in the anterior maxilla: a cone beam computed tomography study," Journal of Prosthodontics, vol. 27, no. 4, pp. 321-328, 2018.

[42] H. Sheerah, B. Othman, A. Jaafar, and A. Alsharif, "Alveolar bone plate measurements of maxillary anterior teeth: a retrospective cone beam computed tomography study, AlMadianh, Saudi Arabia," The Saudi Dental Journal, vol. 31, no. 4, pp. 437-444, J2019.

[43] O. Adiguzel, C. Aktuna Belgin, S. Falakaloglu, S. Cangul, and Z. Akkus, "Maxillary cortical bone thickness in a SouthEastern anatolian population: a cone-beam computed tomography study," Medical Science Monitor, vol. 23, pp. 5812-5817, 2017.

[44] M. Cassetta, A. A. Sofan, F. Altieri, and E. Barbato, "Evaluation of alveolar cortical bone thickness and density for orthodontic mini-implant placement," Journal of Clinical and Experimental Dentistry, vol. 5, no. 5, pp. e245-52, 2013.

[45] J. Gakonyo, A. Mohamedali, and E. Mungure, "Cone beam computed tomography assessment of the buccal bone thickness in anterior maxillary teeth: relevance to immediate implant placement," The International Journal of Oral \& Maxillofacial Implants, vol. 33, no. 4, pp. 880-887, 2018.

[46] T. Usui, S. Uematsu, H. Kanegae, T. Morimoto, and S. Kurihara, "Change in maximum occlusal force in association with maxillofacial growth," Orthodontics and Craniofacial Research, vol. 10, no. 4, pp. 226-234, 2007.

[47] H.-C. Lim, D.-U. Kang, H. Baek et al., "Cone-beam computed tomographic analysis of the alveolar ridge profile and virtual implant placement for the anterior maxilla," Journal of Periodontal \& Implant Science, vol. 49, no. 5, pp. 299-309, 2019.
[48] H.-M. Wang, J.-W. Shen, M.-F. Yu, X.-Y. Chen, Q.-H. Jiang, and F.-M. He, "Analysis of facial bone wall dimensions and sagittal root position in the maxillary esthetic zone: a retrospective study using cone beam computed tomography," The International Journal of Oral \& Maxillofacial Implants, vol. 29, no. 5, pp. 1123-1129, 2014.

[49] R. Amid, K. Rahimipour, M. Namdari, and M. Kadkhodazadeh, "Comparison of the efficacy of digital caliper and a newly designed digital bone gauge for measurement of edentulous alveolar ridge width," Journal of Dental School, vol. 35, no. 3, pp. 78-80, 2017. 